(C) 2022, The Authors. Published by Elsevier Inc. and Fass Inc. on behalf of the American Dairy Science Association ${ }^{\circledR}$. This is an open access article under the CC BY license (http://creativecommons.org/licenses/by/4.0/).

\title{
Impact of gonadotropin-releasing hormone administration at the time of artificial insemination on conception risk and its association with estrous expression
}

\author{
Tracy A. Burnett, $\odot$ Augusto M. L. Madureira, $\odot$ Janet W. Bauer, $\odot$ and Ronaldo L. A. Cerri ${ }^{\star}$ \\ Faculty of Land and Food Systems, University of British Columbia, Vancouver V6T 1Z4, Canada
}

\begin{abstract}
Cows with reduced estrous expression have compromised fertility. The aim of this study was to determine whether the administration of $\mathrm{GnRH}$ at the time of artificial insemination (AI) would affect ovulation rates and the fertility of animals expressing estrous behavior of lesser intensity. Cows were enrolled at the time of estrus from 3 farms $(\mathrm{n}=2,607$ estrus events; farm A: 1,507, farm B: 429, farm C: 671) and randomly assigned to receive $\mathrm{GnRH}$ at $\mathrm{AI}$ or not (control). The intensity of estrous expression, monitored through leg-mounted activity monitors, was determined using the maximum activity during estrus; estrous expression was categorized as greater or lower relative to the farm median. On farm A, cows were assessed at alert, and $24 \mathrm{~h}, 48 \mathrm{~h}$, and $7 \mathrm{~d}$ post-alert for ovulation using ultrasonography. Pregnancy per AI was confirmed at $35 \pm 7$ d post-estrus for cows that were inseminated. Differences between treatments were tested using the GLIMMIX procedure of SAS. Treatment with GnRH at the time of AI increased pregnancy per AI (41.3 \pm 1.6 vs. $35.7 \pm 1.7 \%)$. An interaction between treatment and estrous expression on pregnancy per AI was found. Control cows with greater estrous expression had greater pregnancy per AI than those with lesser expression, whereas GnRH administration increased pregnancy per AI for cows with lesser estrous expression but not those with greater expression $(\mathrm{GnRH}$, greater intensity: $43.5 \pm 2.1 ; \mathrm{GnRH}$, lesser intensity: $37.8 \pm 2.2$; control, greater intensity: $42.6 \pm 2.2$; control, lesser intensity: $31.0 \pm 2.2 \%)$. A higher proportion of cows with greater estrous expression that were administered $\mathrm{GnRH}$ at AI were found to ovulate by $48 \mathrm{~h}$ and $7 \mathrm{~d}$ post-estrus; however, ovulation of cows with lesser estrous expression was unaffected by GnRH administration. In conclusion, fertility of cows with reduced estrous expression may be increased using $\mathrm{GnRH}$ at the time of AI; however,
\end{abstract}

Received January 15, 2021.

Accepted March 29, 2021.

*Corresponding author: ronaldo.cerri@ubc.ca increased ovulation rates do not seem to be the direct mechanism behind this relationship.

Key words: estrous expression, fertility, gonadotropinreleasing hormone

\section{INTRODUCTION}

Achieving high reproductive performance is a primary goal on commercial dairy farms. Different reproductive management practices are available to producers, but automated activity monitors (AAM) are being adopted as a sustainable alternative or complement to visual heat detection and systematic timed AI. In a recent Canadian survey, half of the farmers with freestall herds reported using AAM to aid in estrus detection in at least a portion of their herd (Denis-Robichaud et al., 2016). Despite the growing interest in using this technology, challenges remain regarding interpretation of the data to optimize breeding decisions.

The occurrence of estrus has been shown to improve fertility of timed AI protocols by increasing conception rates (Galvão et al., 2004; Pereira et al., 2014) and reducing pregnancy losses (Galvão et al., 2004; Pereira et al., 2014, 2016). Similarly, benefits of estrous expression for both donor heifers (Madureira et al., 2020) and recipient cows (Jinks et al., 2013; Pereira et al., 2016) participating in embryo transfer have been noted. Not only has the occurrence of estrus been shown to affect fertility, but the intensity of estrous expression has also been associated with fertility when timed AI protocols are implemented (Madureira et al., 2019) and at spontaneously occurring estrus events (Madureira et al., 2015). Recently, quantification of different behavioral changes associated with estrus, such as walking activity (López-Gatius et al., 2005; Madureira et al., 2015), lying behavior (Silper et al., 2017), and activity measured using neck movement (Madureira et al., 2015; Burnett et al., 2017, 2018) measured using AAM have been associated with fertility.

In addition to conception, ovulation timing and failure have been shown to differ with estrous expression. Cows with lesser estrus intensity (Burnett et al., 2018) and shorter duration of estrus (Hockey et al., 2010; 
Valenza et al., 2012; Stevenson et al., 2014) have been associated with shorter intervals from the time of AAM estrus alert to ovulation. Moreover, less estrous expression has also been associated with increased ovulation failure both at spontaneous estrus events (Burnett et al., 2018) and at timed AI (Silper et al., 2017; Madureira et al., 2019). The occurrence of estrus at the end of timed AI protocols using tail chalk has also reported to increase ovulation rates (Galvão et al., 2004; Pereira et al., 2014).

Previously, GnRH has been shown to indirectly cause ovulation through the action of LH (Thatcher et al., 1993). Administration of GnRH at the time of AI has been studied for its effects on pregnancy per AI, but findings have been mixed for both first service and repeat breeders (first service reviewed by Mee et al., 1990, and repeat breeders reviewed by Stevenson et al., 1990). However, no research has been carried out to determine the effects of different intensities of estrous expression with and without GnRH administration on fertility.

Upon reviewing the available literature, we suggest that cows with lesser estrous expression may have compromised fertility due to improper ovulation times or ovulation failure (Stevenson et al., 2014; Burnett et al., 2018). Thus, the objective of this study was to determine whether the fertility of spontaneous estrus events with lesser estrous expression increases when cows are stimulated to ovulate when administered $\mathrm{GnRH}$ at the time of AI. We hypothesized that the administration of GnRH to cows at the time of AI would decrease ovulation failure and increase fertility in cows showing lesser intensity of estrous expression, but not in cows showing greater intensity of estrous expression.

\section{MATERIALS AND METHODS}

This experiment was conducted from February 2017 until October 2018 on 3 commercial farms, one of which was the University of British Columbia's Dairy Education and Research Centre, in Agassiz, British Columbia, Canada. All procedures were approved by the Animal Care Committee of the University of British Columbia (protocol no. A18-0039).

\section{Animals and Housing}

This study took place on 3 commercial dairy farms located in the lower Fraser Valley region of British Columbia. A total of 2,709 episodes of estrus (farm A: 1,591; farm B: 439; farm C: 679 ) were used from 990 lactating Holstein cows (farm A: 430; farm B: 241; farm C: 319 ); an average (mean \pm SD) of $2.6 \pm$ 1.9 episodes per cow. On farms $\mathrm{A}$ and $\mathrm{B}$, cows were housed in wood-framed barns with a freestall design, equipped with deep sand-bedded stalls, fans, and a manure scraper. On farm C, stalls were bedded with sawdust, and manure management used a flush system. On 2 farms, cows were milked twice daily at $0500 \mathrm{~h}$ and $1500 \mathrm{~h}$ within conventional milking parlors, and the other used automated milking robots (Monobox; GEA Farm Technologies). Fresh TMR was delivered twice daily on 2 farms at approximately $0700 \mathrm{~h}$ and $1600 \mathrm{~h}$, and on the third farm fresh feed was delivered once daily at approximately $0700 \mathrm{~h}$. The TMR on each farm was formulated following the Nutrient Requirements of Dairy Cattle guidelines (NRC, 2001) to meet or exceed the requirements of a $620-\mathrm{kg}$ Holstein cow producing 40 $\mathrm{kg} / \mathrm{d}$ of $3.5 \%$ fat-corrected milk; all cows on all farms had ad libitum access to both TMR and water.

All cows had their BCS and gait score (GS) assessed within $3 \mathrm{~d}$ of their estrus alert. Body condition and gait were scored using 5-point scales from thin (1) to obese (5) and sound (1) to severely lame (5), as outlined by Edmonson et al. (1989) and Flower and Weary (2006), respectively. Cows were later classified as thin $(<2.75)$, average $(2.75)$, or moderate $(>2.75)$ and sound $(\leq 2)$ or lame $(>2)$ based on BCS and GS, respectively. Health and production information was collected by dairy herd personnel with the assistance of the herd veterinarian, and confirmed and recorded by the project leader from the on-farm Dairy Comp 305 software (Valley Agricultural Software). The mean DIM, parity, BCS, GS, and 305-d mature-equivalent yield are summarized by farm (see Table 1).

\section{Study Design}

In this randomized controlled trial, cows were continuously monitored using leg-mounted pedometers (farm A: Afi PedoPlus, Afikim; farms B and C: Rescounter II, GEA Farm Technologies), fitted immediately after calving. Animals were enrolled in the study when the monitor identified them as having crossed the alert threshold, as set by the manufacturer of each AAM system. The thresholds for estrus alerts set by each company differed, but both systems compared the cows' current activity to their own basal activity. The threshold created by the Afi PedoPlus monitor relies on criteria for both a relative increase in steps from baseline in addition to the number of steps within 1-h blocks, where blocks with lower steps per hour require a higher relative increase in steps from baseline, and vice versa. For example, a cow with 0 to 49 steps $/ \mathrm{h}$ would require an increase in steps of $180 \%$ to be alerted, whereas a cow with $700+$ steps/h would require an increase of only $135 \%$. The threshold created by Rescounter II relied on an increase in steps relative to 
Table 1. Cow characteristics [mean $\pm \mathrm{SD}$ with ranges (minimum-maximum) below, where possible] for all estrus events that were inseminated within the study, separated by farm

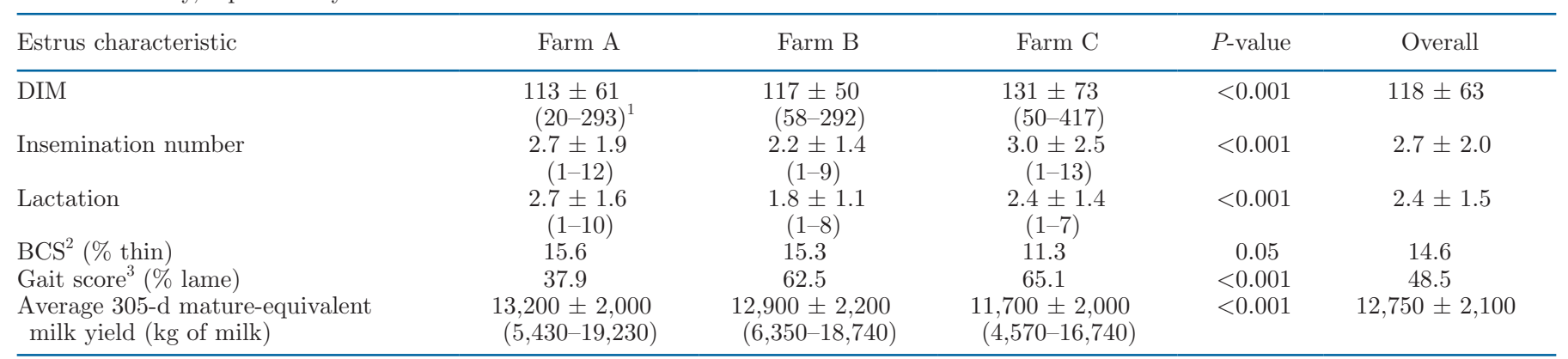

${ }^{1}$ Events less than the voluntary wait period of 60 DIM were not inseminated and thus not used for pregnancy outcome data.

${ }^{2}$ Cows with a BCS of $<2.75$ were considered thin.

${ }^{3}$ Cows with a gait score of $>2$ were considered lame.

baseline within 2-h blocks, where an increase in steps of $180 \%$ was considered a suspicious alert and an increase of $230 \%$ was considered a heat alert; 2 consecutive suspicious alerts would also result in a heat alert. The AAM were checked once (farm C) or twice (farms A and B) daily during milking times for cows in estrus, and cows were inseminated either in the morning (farm C) or using the a.m./p.m. rule (farms A and B). At the time of AI, cows were randomly assigned to receive an intramuscular injection of $100 \mu \mathrm{g}$ of gonadorelin (GnRH; Factrel, Zoetis; $2 \mathrm{~mL}$ ). Randomization of the treatment on farm A was carried out by alternating between control and GnRH treatments by the chronological order in which alerts arose. On farms B and $\mathrm{C}$, treatments were alternated by calendar day, where cows bred on even days of the month received $\mathrm{GnRH}$ on farm B and were control on farm C, and the opposite treatment was given on odd days of the month, respectively. On all farms, allocation of treatment was carried out systematically in the manner described, and thus knowledge of the intensity of estrus, ovulation timing, or other pertinent information about the cow that may have biased the treatment was unknown at the time of allocation. Implementation of the treatment was carried out by the lead researchers of this manuscript on farms $\mathrm{A}$ and $\mathrm{C}$, and by farm personnel on farm B. Peak activity (see Madureira et al., 2015) was used to describe the intensity of the expression of estrus using the data from the AAM. Peak activity was defined as the maximum activity during an estrus episode.

\section{Determination of Estrus, Ovulation, and Pregnancy}

A subset of estrus events ( $\mathrm{n}=1,498$ from 430 cows) on farm A were assessed for the occurrence of ovulation at $24 \mathrm{~h}(\mathrm{n}=894), 48 \mathrm{~h}(\mathrm{n}=1,274)$, and $7 \mathrm{~d}(\mathrm{n}=$ 1,487) post-alert; all estrus events were not assessed at all 3 time points. Cows had their ovaries examined by ultrasound per rectum (Ibex Pro; E. I. Medical Imaging) using a 7.5- $\mathrm{MHz}$ linear-array rectal probe at enrollment and $24 \mathrm{~h}, 48 \mathrm{~h}$, and $7 \mathrm{~d}$ post-alert (farm A only). The presence and diameter of the 3 largest follicles and corpora lutea were measured using the digital calipers of the ultrasound and recorded at each examination. Examinations at alerts were used to determine whether the cow was truly in estrus; exams at 24 and $48 \mathrm{~h}$ were used to determine general timing of ovulation; and d-7 examinations were used to confirm ovulation. Exams for ovulation were performed at the milking closest to the desired time point, such that 24-h exams occurred 24.0 $\pm 4.6 \mathrm{~h}$ post-alert and 48 -h exams $49.8 \pm 5.2$ post-alert. Cows were classified as in estrus if they had at least 1 dominant preovulatory follicle greater than $15 \mathrm{~mm}$ and an absence of corpus luteum or a corpus luteum that was less than $25 \mathrm{~mm}$ at the time of the estrus alert. Ovulation was determined by the disappearance of the dominant preovulatory follicle. A new corpus luteum at d 7 was used to confirm ovulation for true estrus alerts where ovulation was detected. For true estrus alerts where ovulation was not detected by $48 \mathrm{~h}$ post-alert, the absence of a new corpus luteum at $d 7$ was indicative of failed ovulation. For false alerts, the absence of a new corpus luteum at $d 7$ was used to confirm that the estrus alert was correctly classified as false. In the event that both ovaries had only small structures at alert, but a new corpus luteum was formed by $7 \mathrm{~d}$, cows were assumed to have ovulated before the first examination. Thus, cows with a large corpus luteum $(>25 \mathrm{~mm})$ at the time of alert as well as cows with an absence of both a preovulatory follicle $(>15 \mathrm{~mm})$ and formation of a new corpus luteum on $\mathrm{d} 7$ were classified as false alerts.

Insemination interval was determined for 2 farms (farms A and C), as insemination times were consistent each day. On farm A, insemination occurred between 0800 and $1000 \mathrm{~h}$ in the morning, and 1600 and 1800 
$\mathrm{h}$ in the afternoon. On farm $\mathrm{C}$, cows were inseminated once per day between 0800 and $1200 \mathrm{~h}$. To determine the insemination interval, standardized times of 0900 , 1500 , and $1000 \mathrm{~h}$ were used for farm A morning, farm $\mathrm{A}$ afternoon, and farm $\mathrm{C}$, respectively, and compared with the onset of estrus as determined using the AAM of each farm.

On all farms, pregnancy diagnosis was performed at $35 \pm 7 \mathrm{~d}$ post-AI for the detection of a viable embryo (presence of a heartbeat). Diagnosis was carried out by the regular herd veterinarian of each farm.

\section{Statistical Analyses}

All statistical analyses in this study were carried out using SAS Studio (version 5.1; SAS Institute Inc.) with estrus episode as the experimental unit. The required sample size of 2,080 estrus events was calculated to find a difference in pregnancy per AI of 32 versus $42 \%$ and a required sample size of 944 estrus events to find a difference in ovulation rate of 98 versus $91 \%$ based on Burnett et al. (2018), assuming 95\% confidence and $80 \%$ power, including clustered data per cow (2 estrus events per cow), confounders (intraclass correlation coefficient $=0.3$ ), and the assessment of an interaction between the administration of $\mathrm{GnRH}$ and the intensity of estrous expression (Dohoo et al., 2003; Leon and Heo, 2009).

Estrus events deemed false alerts were excluded from the analysis. Inseminations were carried out on $87.6 \%$ $(2,301 / 2,626)$ of estrus events, and the remaining $12.4 \%$ were not inseminated due to management reasons (e.g., events occurring before the voluntary wait period of 60 DIM) but used for ovulation data on farm A. Pregnancy diagnosis was missing for $2.0 \%(46 / 2,301)$ of events, and $6.9 \%(182 / 2,626)$ of events were missing estrous expression data due to faults in the AAM. Events lacking all outcome variables (pregnancy outcome and ovulation data) were removed, thus equating to a total of 2,607 estrus events being used in the final analyses (farm A: 1,507; farm B: 429; farm C: 671). In total, $50.0 \%(1,305 / 2,607)$ received the $\mathrm{GnRH}$ treatment [farm A: 50.4 (760/1,507); farm B: 53.6 (230/429); farm C: $46.9 \%(315 / 671)]$. Numbers of events used in each model are indicated in Table 2 .

Before all analyses, data were checked for normality using the UNIVARIATE procedure and probability distribution plots. Pregnancy per AI and proportion of cows that ovulated by $24 \mathrm{~h}, 48 \mathrm{~h}$, and $7 \mathrm{~d}$ postalert were used as dependent variables and were tested for the effects of GnRH treatment, estrous expression, insemination interval (pregnancy per AI model only),

Table 2. Description of final linear mixed regression models in which estrus event was used as the experimental unit and cow within farm as the random effect for the outcome variables of pregnancy per AI, ovulation rate, and ovulation by $24 \mathrm{hr}, 48 \mathrm{hr}$, and $7 \mathrm{~d}$ post-AI

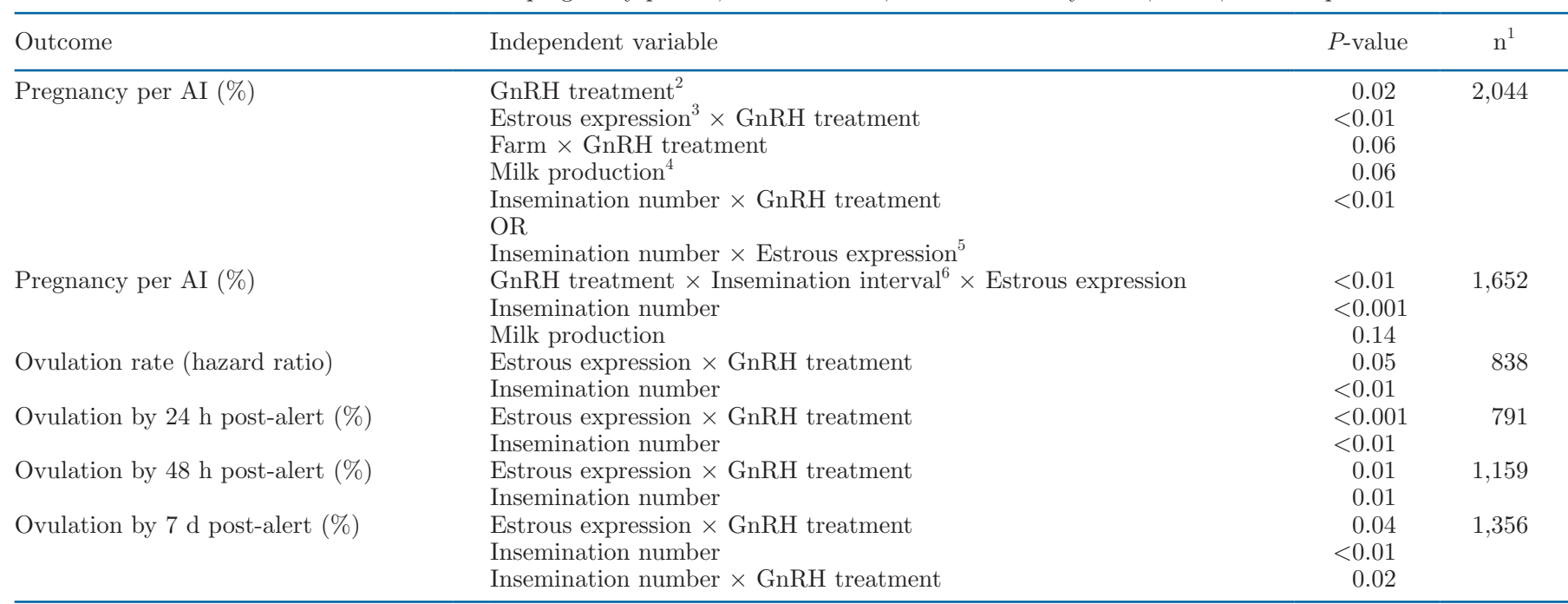

\footnotetext{
${ }^{1}$ Number of estrus events included within each analysis. Numbers less than enrollment are due to missing data.

${ }^{2}$ The GnRH treatment group was administered GnRH at the time of AI; the control group was not administered GnRH at AI.

${ }^{3}$ Estrous expression refers to the maximum change in activity measured by an AAM during estrus. Estrous expression was classified as greater or lesser intensity using the median of each farm.

${ }^{4}$ Milk production was measured as the $305-\mathrm{d}$ mature-equivalent yield in $\mathrm{kg}$.

${ }^{5}$ Insemination by GnRH treatment and by estrous expression were modeled separately due to collinearity.

${ }^{6} \mathrm{~A}$ separate model was used to assess the association of insemination interval and pregnancy due to insemination interval being collected only for a subgroup of cows (farms A and C only).
} 
parity, BCS, GS, DIM, insemination number, and milk production via ANOVA with cow nested in farm as a random effect, using the GLIMMIX procedure. Each estrus event was categorized as having greater- or lesser-intensity estrous expression using the median peak activity of each farm; categorization by farm was carried out to account for different AAM used between farms. Cows with more than 1 lactation were classified as multiparous, and those with only 1 lactation were considered primiparous.

Ovulation rate was calculated as the hazard risk of ovulation by $7 \mathrm{~d}$ post-estrus using the PHREG procedure. Cox proportional hazard regression models included days in which the cow had not yet ovulated, relative to the automated estrus alert, as the outcome variable, and treatment, estrous expression, parity, BCS, GS, milk production, and insemination number were used as explanatory variables. Observations were right-censored at $7 \mathrm{~d}$ if ovulation was not confirmed at any of the post-estrus ultrasound exams. Survival curves were drawn from the proportion of cows that had not ovulated at each time point, given by the LIFETEST procedure.

All multivariable models were constructed using the variables as described, and manual backward stepwise elimination was used, where variables were retained with $P \leq 0.15$. Interactions were tested between all variables selected in the final model and kept if $P<$ 0.05. Final models are summarized in Table 2.

\section{RESULTS}

Treatment with GnRH at the time of AI increased pregnancy per AI $(41.3 \pm 1.6$ vs. $36.7 \pm 1.6 \% ; P=0.02)$. In addition, we noted an interaction between treatment and estrous expression on pregnancy per AI. Within the control group, cows with greater estrous expression had greater pregnancy per AI than those with lesser expression, whereas GnRH administration increased pregnancy per AI for cows with reduced estrous expression but not those with greater expression (Figure 1; $P<0.01)$. Despite differences in herd characteristics (Table 1), we detected no effect of farm on the interaction between estrous expression and treatment. We found a tendency for an interaction between farm and treatment, where an effect of treatment alone occurred for pregnancy per AI on farm B (farm A pregnancy per AI: $\mathrm{GnRH}=39.7 \pm 2.1$, control $=37.1 \pm 2.2$; farm $\mathrm{B}: \mathrm{GnRH}=48.4 \pm 3.4$, control $=34.3 \pm 3.7$; farm C: $\mathrm{GnRH}=35.9 \pm 2.8$, control $=35.7 \pm 2.6 \% ; P=0.06$ ). A tendency was detectable for 305-d mature-equivalent milk yield to be associated with pregnancy per AI, where every $1,000 \mathrm{~kg}$ increase in yield was associated with a $1.0 \%$ decrease in pregnancy per AI $(P=0.06)$.
Pregnancy per AI was not found to be associated with parity, DIM, GS, or BCS.

Interactions between insemination number and treatment, as well as insemination number and estrous expression, were observed for pregnancy per AI. In general, as insemination number increased, pregnancy per AI decreased. However, at lower insemination numbers postpartum, GnRH administration (Figure 2; $P<0.01$ ) and estrous expression (Figure 3; $P<0.001$ ) appeared to provide greater benefits than at greater insemination numbers postpartum. However, only $10 \%$ of events occurred at an insemination number greater than 5 . After removing these extreme values, we found a tendency for the interaction between insemination number and estrous expression to be maintained (Figure $3 ; P=$ 0.07 ), but the interaction between insemination number and treatment was no longer observed (Figure 2; $P=$ 0.34 ). Hence, the benefit of using GnRH at the time of AI was consistent among insemination numbers, at least until 5 inseminations postpartum.

A 3-way interaction was observed between $\mathrm{GnRH}$ treatment, estrous expression, and insemination interval (Figure $4 ; P<0.01$ ). Within the control group, insemination interval was observed to have a negative association with pregnancy per AI for cows with reduced estrous expression, but not for cows with greater estrous expression. Within the GnRH group, the negative association of insemination interval for cows with reduced estrous expression was dampened.

An interaction between $\mathrm{GnRH}$ administration and estrous expression was observed for the rate at which cows ovulated, where the hazard risk of ovulation was greatest for cows with greater estrous expression receiving $\mathrm{GnRH}$ (Figure 5; $P=0.05$ ). The rate of ovulation was also associated with insemination number, whereby

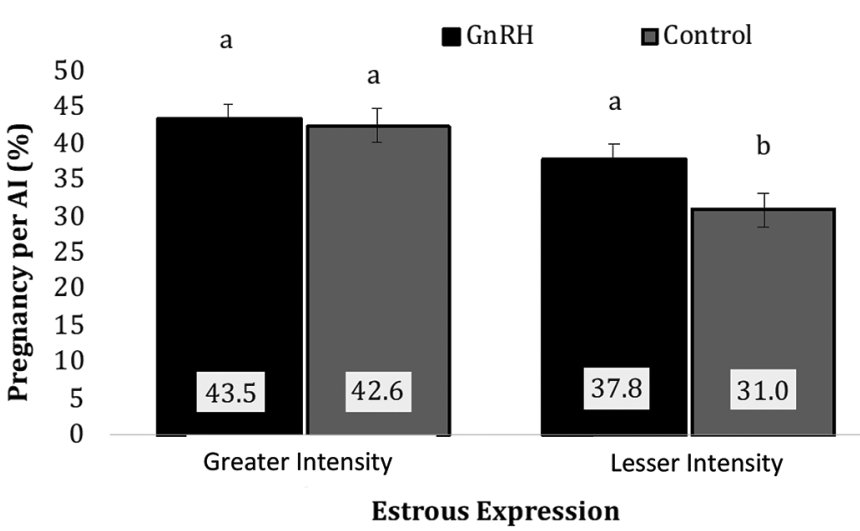

Figure 1. The influence of GnRH administration at the time of AI on pregnancy per AI relative to the intensity of estrous expression $(\mathrm{LSM} \pm \mathrm{SE})$. Lowercase letters $\mathrm{a}$ and $\mathrm{b}$ denote differences $(P<0.05)$. Greater Intensity $=$ estrous expression greater than the median of each farm. Lesser Intensity $=$ estrous expression lesser than the median. 

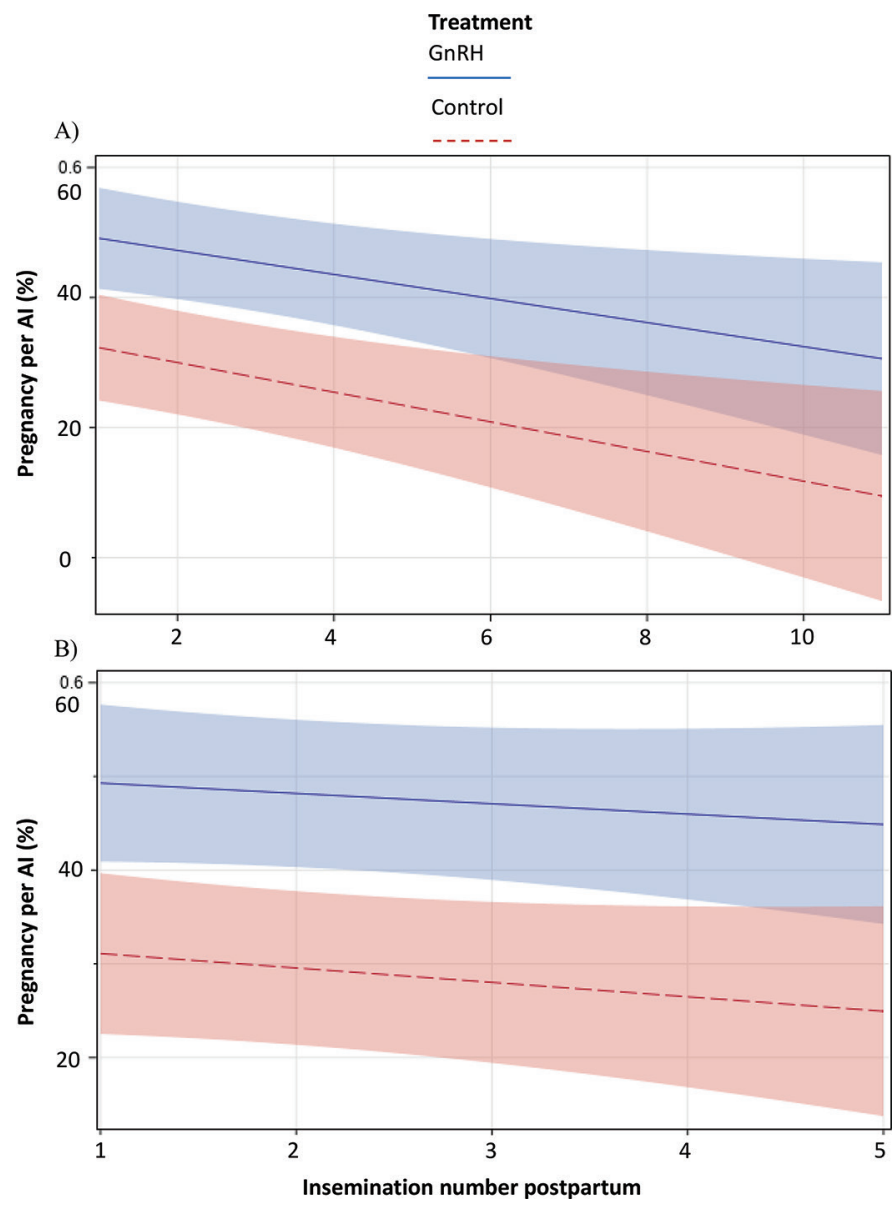

Figure 2. The interaction, with $95 \% \mathrm{CI}$, of the effect of $\mathrm{GnRH}$ administration at the time of AI with increasing insemination number for the entire study $(2,044$ events; panel A; $P<0.01)$ and when only including insemination numbers from 1 to 5 postpartum (1,836 events; panel $\mathrm{B} ; P=0.34$ ) on pregnancy per AI of lactating Holstein cows.

every unit increase in insemination number was associated with decreased hazard risk of ovulation by $7 \mathrm{~d}$ post-estrus (hazard ratio $=0.94 ; P<0.01$ ). Furthermore, when considering the proportion of cows that ovulated by $24 \mathrm{~h}, 48 \mathrm{~h}$, and $7 \mathrm{~d}$ post-estrus, interactions between $\mathrm{GnRH}$ administration and estrous expression were also found. By $24 \mathrm{~h}$ post-alert, cows with greater estrous expression had lower ovulation rates than those with lesser estrous expression among control cows, but we detected no differences in the proportion of cows in the GnRH treatment that ovulated according to estrous expression categories (Figure 6; $P<0.001$ ). By $48 \mathrm{~h}(P=0.01)$ and $7 \mathrm{~d}(P=0.04)$ post-estrus, cows with greater estrous expression receiving GnRH had greater ovulation rates than all other groups (Figure $6)$. Increasing insemination number was observed to be associated with a lower proportion of cows ovulating by $24 \mathrm{~h}(P<0.01), 48 \mathrm{~h}(P=0.02)$, and $7 \mathrm{~d}(P<$ $0.01)$ post-estrus. Additionally, an interaction between
GnRH administration and insemination number was found on the proportion of cows ovulating by $7 \mathrm{~d}$ postestrus, where the negative effect of increasing insemination number on the proportion of cows ovulating by $7 \mathrm{~d}$ post-estrus was dampened with the use of $\mathrm{GnRH}$ at the time of AI (Figure 7; $P=0.02$ ). Parity, GS, BCS, DIM, and 305-d lactation yield were not associated with differences in the proportion of cows that ovulated by 24 h, $48 \mathrm{~h}$, or $7 \mathrm{~d}$ post-alert.

\section{DISCUSSION}

This study demonstrated that the outcome of administrating $\mathrm{GnRH}$ at the time of $\mathrm{AI}$ at spontaneous estrus events may be reliant on the intensity of estrous

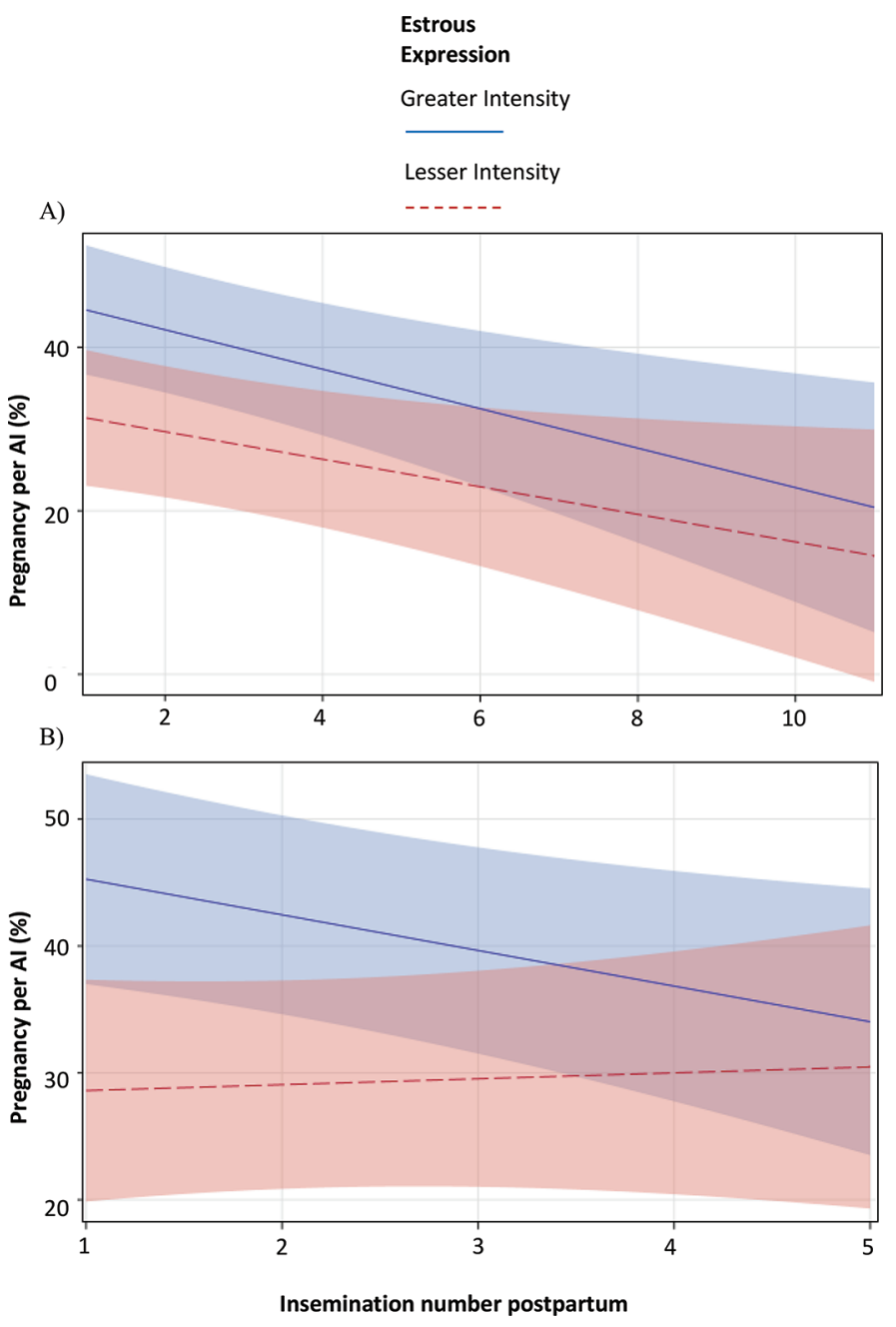

Figure 3. The interaction, with $95 \% \mathrm{CI}$, of the association of estrous expression at increasing insemination number for the entire study $(2,044$ events; panel A; $P<0.001)$ and when only including insemination numbers from 1 to 5 postpartum (1,836 events; panel $\mathrm{B} ; P=0.07)$ on pregnancy per AI of lactating Holstein cows. Estrous expression was defined as greater or lesser relative to the farm median. 
expression. Cows with lesser estrous expression benefited from GnRH administration, whereas cows with greater estrous expression did not. To the best of our knowledge, the impact of this interaction on pregnancy per AI has not previously been reported in dairy cattle. A tendency for an overall effect of $\mathrm{GnRH}$ treatment (irrespective of estrous expression) on pregnancy per AI has been reported in previous research (Stevenson et al., 1990; López-Gatius et al., 2006). In the present study, this association varied by farm, similar to a study by Anderson and Malmo (1985), where 2 out of the 3 farms failed to show an overall influence of GnRH. Interestingly, the interaction of estrous expression and GnRH administration on pregnancy per AI was consistent on all 3 participating farms in the current study, even though all farm characteristics were not consistent, suggesting that administering GnRH to cows with suboptimal estrous expression is a practice that can be adopted successfully under varying condi- tions. A large proportion of cows in this study were classified as having clinical lameness. This may be linked to different aspects of the housing environment found on each farm (Solano et al., 2015), or it may be due to the sampling of only nonpregnant cows. Lameness has been reported to occur more predominantly during early and mid-lactation (Green et al., 2002; Bicalho et al., 2008), which coincides with the breeding period.

A similar study, using beef cattle and tail chalk, found comparable results, where cows with lesser estrous expression at the end of a timed AI protocol had greater pregnancy per AI when receiving GnRH at AI compared with cows not receiving GnRH (Rodrigues et al., 2019). In concordance with our study, a metaanalysis of 40 trials, including over 19,000 cows, found an overall positive impact of GnRH application at the time of AI (Morgan and Lean, 1993). Those authors argued that the variation noted in many of the included studies was due in large part to small samples sizes, but

\section{Estrous \\ Expression}

\section{Greater Intensity}

\section{Lesser Intensity}

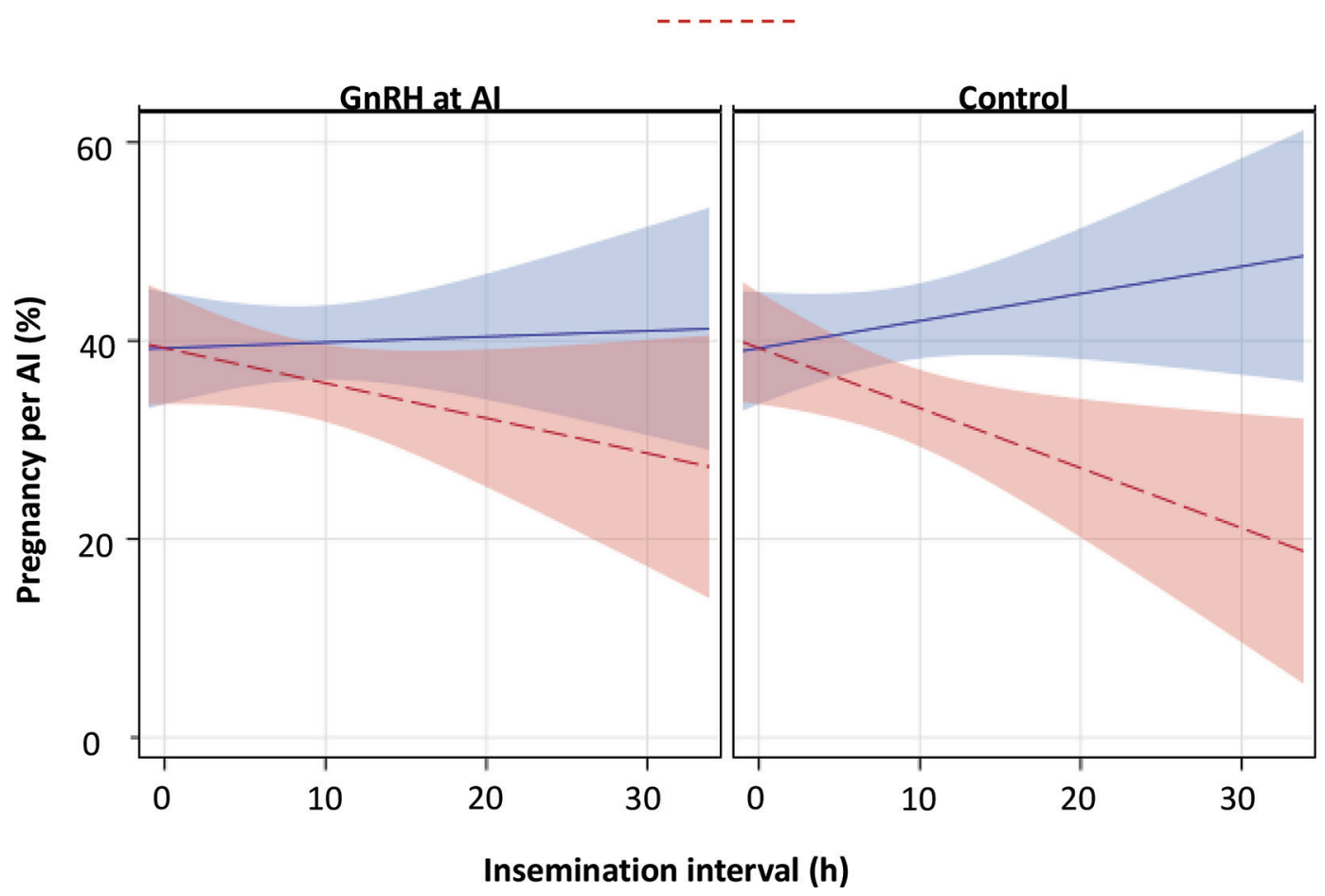

Figure 4. The interaction, with $95 \%$ CI, of insemination interval (h) with estrous expression on pregnancy per AI for cows administered $\mathrm{GnRH}$ at the time of insemination and cow within the control group ( $\mathrm{n}=1,652 ; P<0.01)$. Insemination interval was determined as the time between the estrus alert of the automated activity monitor and insemination time. Estrous expression was defined as greater or lesser relative to the farm median. 


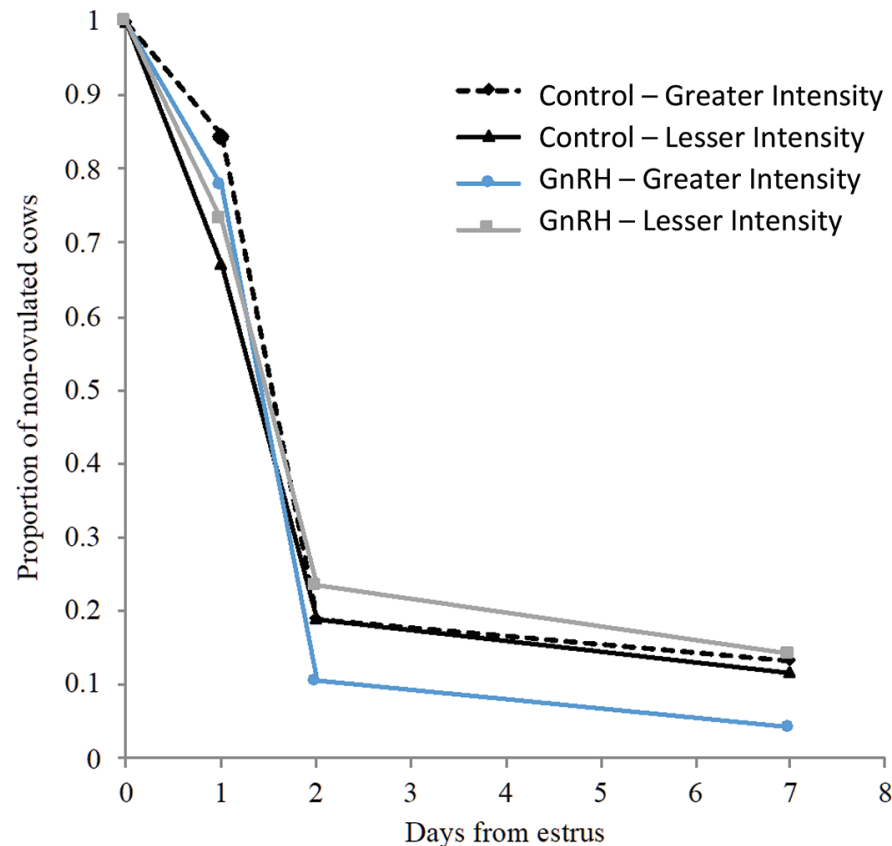

Figure 5. Survival curve analysis for ovulation for the interaction between $\mathrm{GnRH}$ administration at the time of $\mathrm{AI}$ and estrous expression as measured using automated activity monitors using 838 estrus events from lactating Holstein cows $(P=0.05)$. Greater Intensity $=$ estrous expression greater than the median of each farm. Lesser Intensity $=$ estrous expression lesser than the median.

we suggest that some of the variability may be due to differences in estrous expression.

Our original hypothesis that GnRH administration would increase fertility of cows with reduced estrous expression through increased ovulation and corpus luteum function was not supported by our findings. Although we observed differences in the proportion of cows that had ovulated by $24 \mathrm{~h}, 48 \mathrm{~h}$, and $7 \mathrm{~d}$ post-estrus, the overall rate of ovulation was increased by the administration of $\mathrm{GnRH}$ only in cows with greater estrous expression. Interestingly, this increase in ovulation success was not coupled with increased pregnancy per AI. In fact, the group with greater relative increase in pregnancy per AI (cows with lesser estrous expression), had no changes in ovulation associated with $\mathrm{GnRH}$.

The influence of $\mathrm{GnRH}$ on ovulation rates of cystic cows (Bierschwal et al., 1975; Ijaz et al., 1987; Nanda et al., 1988), during synchronization protocols (Bello et al., 2006; Galvão and Santos, 2010) and as a treatment to induce cyclicity in the early postpartum (Gümen and Seguin, 2003; Bittar et al., 2014), has been thoroughly researched. However, few studies have reported the effects of GnRH at AI on the ovulation rates of spontaneous estrus events. Similar to the current study, but using an estradiol-based timed AI protocol, Rodrigues et al. (2019) reported that the proportion of cows that had ovulated by $7 \mathrm{~d}$ post-AI was unchanged by $\mathrm{GnRH}$ administration at AI among cows with lesser estrous expression. However, in contrast with the current study,

A)

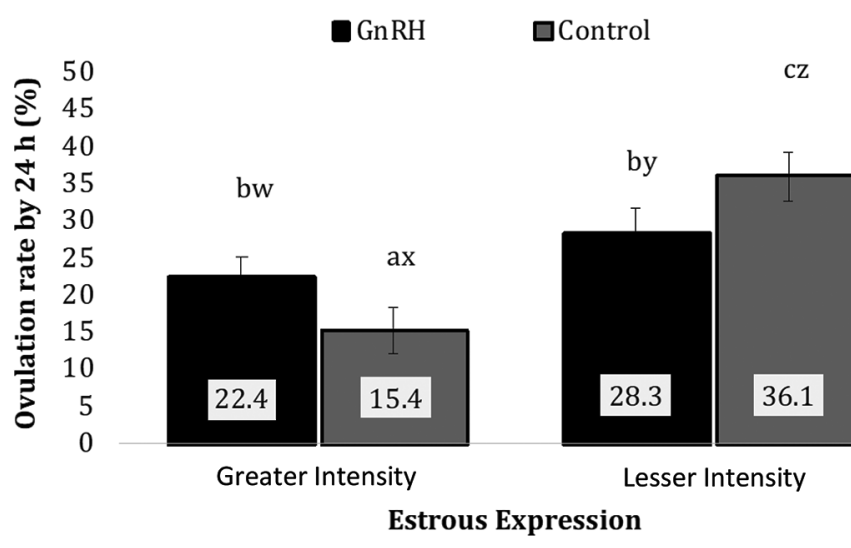

B)

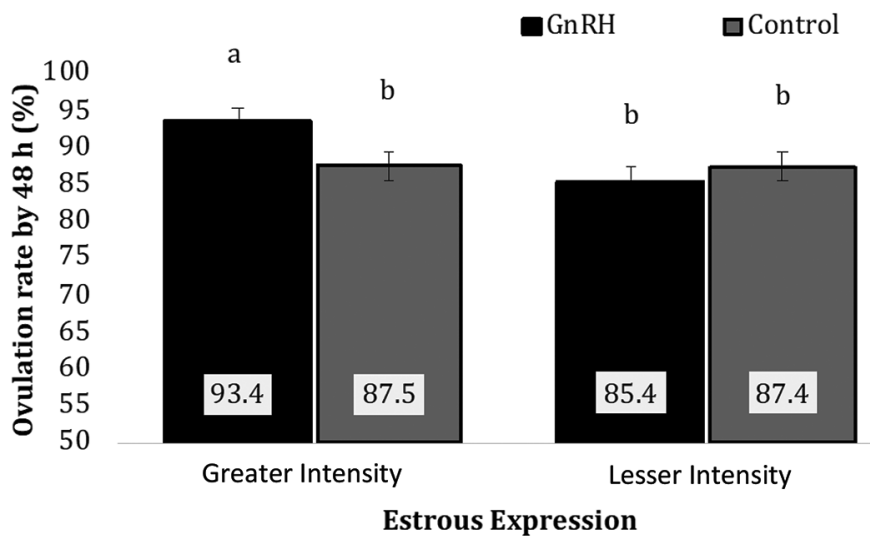

C)

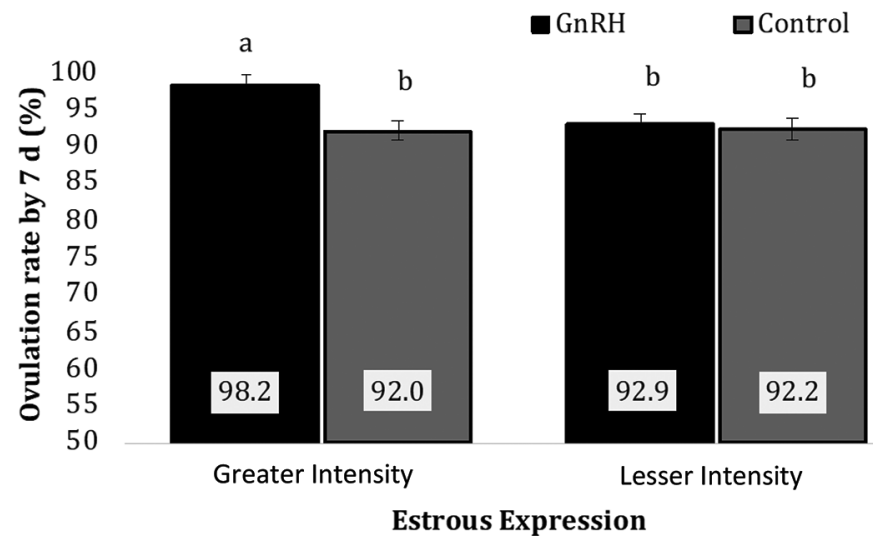

Figure 6. The effect of GnRH administration at the time of AI on ovulation rates by $24 \mathrm{~h}(\mathrm{~A}), 48 \mathrm{~h}(\mathrm{~B})$, and $7 \mathrm{~d}$ post-alert (C) relative to the intensity of estrous expression as measured using an automated activity monitor $(\mathrm{LSM} \pm \mathrm{SE})$. Lowercase letters a and b denote significant differences $(P<0.05) ; \mathrm{w}$ and $\mathrm{x}$, and $\mathrm{y}$ and $\mathrm{z}$ denote tendencies $(0.05<P<0.10)$. Greater Intensity $=$ estrous expression greater than the median of each farm. Lesser Intensity $=$ estrous expression lesser than the median. 
they found that cows with greater estrous expression and without the use of GnRH had greater ovulation rates than cows with lesser estrous expression irrespective of $\mathrm{GnRH}$ treatment. Additionally, the administration of buserelin, a GnRH analog, at the time of AI has also been reported not to affect the interval from the onset of estrus to ovulation (Ryan et al., 1994). The administration of $\mathrm{GnRH}$ is a direct link to ovulation due to its effects on LH secretion and pulse frequency (Bloch et al., 2006). Administration of $\mathrm{GnRH}$ at the onset of estrus in previous studies was found to increase the intensity (both the amplitude and the area under the curve) of the preovulatory LH surge and shorten the interval from the onset of estrus to the LH surge and subsequently ovulation (Kaim et al., 2003). In fact, in that study, the administration of $\mathrm{GnRH}$ at estrus
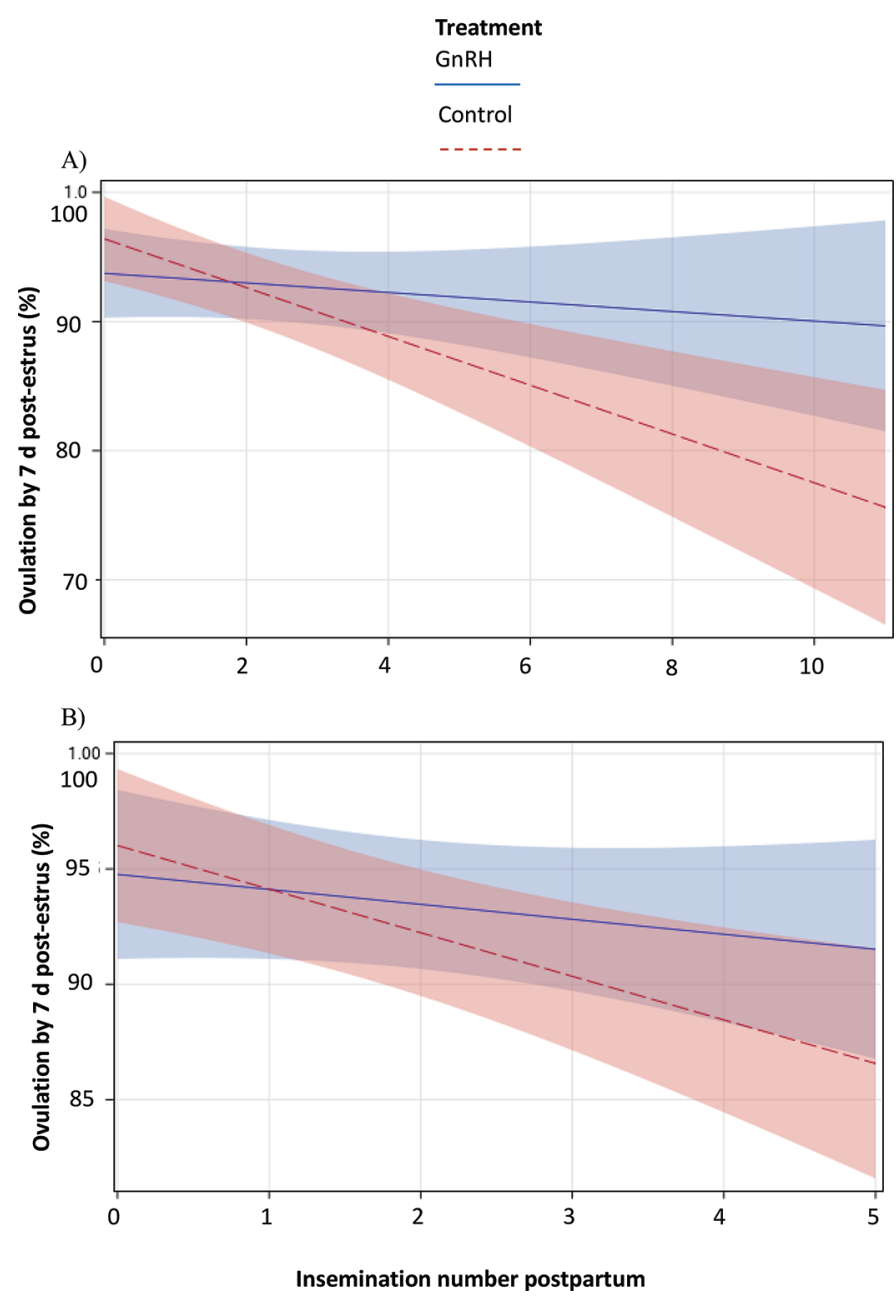

Figure 7. The interaction, with $95 \%$ CI, of the administration of $\mathrm{GnRH}$ at AI with insemination number on the proportion of cows ovulating by $7 \mathrm{~d}$ post-estrus for the entire study ( $\mathrm{n}=1,339$ estrus events; $P=0.02 ; \mathrm{A})$ and when including only insemination number 1 to 5 postpartum $(1,233$ estrus events; $P=0.16$; B). caused a dramatic reduction in the proportion of cows that ovulated more than $30 \mathrm{~h}$ after the onset of estrus, thus shortening the ovulation interval and reducing ovulation failure. Lee et al. (1985) reported that cows receiving $\mathrm{GnRH}$ at first postpartum $\mathrm{AI}$, instead of at onset of estrus, had increased concentrations of LH in the hours following administration, in addition to the naturally occurring LH surge occurring around the onset of estrus; unfortunately, Lee and colleagues did not monitor ovulation rates.

Circulating concentrations of progesterone and estradiol have been shown to affect the intensity and timing of a GnRH-induced LH surge (Stevenson and Pulley, 2016). Cows with increased concentrations of circulating progesterone or decreased concentrations of estradiol at the time of GnRH injection had reduced LH surges and ovulation rates (Stevenson and Pulley, 2016). Additionally, the time from $\mathrm{GnRH}$ injection during a timed AI protocol to the peak concentrations of LH was increased in cows with low progesterone compared with those with high progesterone (Stevenson and Pulley, 2016). Because cows with greater estrous expression have been suggested to have lower progesterone at the time of AI, these results may be similar to those demonstrated by Burnett et al. (2018), where cows with reduced estrous expression had lower ovulation rates, but those that did ovulate had shorter ovulation intervals from the onset of estrus. These associations may help explain why GnRH administration modulated the proportion of cows that had ovulated by $24 \mathrm{~h}, 48 \mathrm{~h}$, and $7 \mathrm{~d}$ postestrus differently among cows with varying intensities of estrous expression. Future research is warranted to determine the relationship between estrous expression, ovulation, and GnRH administration.

It has been reported that the administration of $\mathrm{GnRH}$ or GnRH analogs are more beneficial on repeat breeders than with the first AI postpartum (see meta-analysis by Morgan and Lean, 1993). However, the majority of work discussing the influence of GnRH administration at different service numbers fails to directly compare the interaction of service number with GnRH treatment. Instead, most focus on magnitude changes in conception at each service or use only one population of service number (e.g., only repeat breeders) and then compare their results to previously published works. Although the current study did find GnRH to have less effect with higher services, this may be driven by a lower number of cows being inseminated more than 5 inseminations. Removing more extreme inseminations, we found that $\mathrm{GnRH}$ was consistently associated with an increase in pregnancy per AI irrespective of insemination number. These results are similar to those of Lewis et al. (1990) and Anderson and Malmo (1985), who found no effects of GnRH administration 
on pregnancy per AI at first, second, or third service. In contrast, Ryan et al. (1991) reported that administration of a GnRH analog was most beneficial at 40 to 59 DIM compared with other insemination time points. In Australian herds managed with seasonal calving, GnRH at AI was reported to increase conception risk, but only in cows bred at less than 40 DIM (Shephard et al., 2014), considerably earlier than the voluntary wait period used in our study.

\section{CONCLUSIONS}

This study demonstrates that administration of GnRH at the time of AI improved pregnancy per AI, particularly for cows with lesser estrous expression. Administration of $\mathrm{GnRH}$ altered the proportion of cows that ovulated by 24 and $48 \mathrm{~h}$ and $7 \mathrm{~d}$ post-AI, where only cows with greater estrous expression benefited from receiving $\mathrm{GnRH}$; these changes in ovulation were not correlated with an increase in fertility. Beneficial effects of GnRH for cows with lesser estrous expression was consistent within farm, suggesting that administering $\mathrm{GnRH}$ to cows with suboptimal estrous expression is a practice that can be adopted successfully under varying conditions. Future research is warranted to determine the mechanism responsible for the beneficial relationship between estrous expression and $\mathrm{GnRH}$ administration on the fertility of lactating dairy cows.

\section{ACKNOWLEDGMENTS}

This study was supported by contributions from Zoetis and the Dairy Research Cluster 2 Initiative (Dairy Farmers of Canada, Agriculture and Agri-Food Canada, the Canadian Dairy Network, and the Canadian Dairy Commission). Partial funding was also provided by the Natural Sciences and Engineering Research Council grant NSERC-RGPIN 418672-13, and by the DIREC Program, supported by the British Columbia Dairy Association. The authors also thank Nelson Dinn and all students who assisted with data collection at the University of British Columbia Dairy Education and Research Centre. The authors have not stated any conflicts of interest.

\section{REFERENCES}

Anderson, G. A., and J. Malmo. 1985. Pregnancy rate of cows given synthetic gonadotrophin-releasing hormone at the time of service. Aust. Vet. J. 62:222-224. https://doi.org/10.1111/j.1751-0813 .1985.tb07317.x.

Bello, N. M., J. P. Steibel, and J. R. Pursley. 2006. Optimizing ovulation to first GnRH improved outcomes to each hormonal injection of Ovsynch in lactating dairy cows. J. Dairy Sci. 89:3413-3424. https://doi.org/10.3168/jds.S0022-0302(06)72378-5.
Bicalho, R. C., L. D. Warnick, and C. L. Guard. 2008. Strategies to analyze milk losses caused by diseases with potential incidence throughout the lactation: A lameness example. J. Dairy Sci. 91:2653-2661. https://doi.org/10.3168/jds.2007-0744.

Bierschwal, C. J., H. A. Garverick, C. E. Martin, R. S. Youngquist, T. C. Cantley, and M. D. Brown. 1975. Clinical response of dairy cows with ovarian cysts to GnRH. J. Anim. Sci. 41:1660-1665. https://doi.org/10.2527/jas1975.4161660x.

Bittar, J. H. J., P. J. Pinedo, C. A. Risco, J. E. P. Santos, W. W. Thatcher, K. E. Hencken, S. Croyle, M. Gobikrushanth, C. C. Barbosa, A. Vieira-Neto, and K. N. Galvão. 2014. Inducing ovulation early postpartum influences uterine health and fertility in dairy cows. J. Dairy Sci. 97:3558-3569. https://doi.org/10.3168/ jds.2013-7533.

Bloch, A., Y. Folman, M. Kaim, Z. Roth, R. Braw-Tal, and D. Wolfenson. 2006. Endocrine alterations associated with extended time interval between estrus and ovulation in high-yield dairy cows. J. Dairy Sci. 89:4694-4702. https://doi.org/10.3168/jds.S0022 $-0302(06) 72520-6$.

Burnett, T. A., A. M. L. Madureira, B. F. Silper, A. C. C. Fernandes, and R. L. A. Cerri. 2017. Integrating an automated activity monitor into an artificial insemination program and the associated risk factors affecting reproductive performance of dairy cows. J. Dairy Sci. 100:5005-5018. https://doi.org/10.3168/jds.2016-12246.

Burnett, T. A., L. Polsky, M. Kaur, and R. L. A. Cerri. 2018. Effect of estrous expression on timing and failure of ovulation of Holstein dairy cows using automated activity monitors. J. Dairy Sci. 101:11310-11320. https://doi.org/10.3168/jds.2018-15151.

Denis-Robichaud, J., R. L. A. Cerri, A. Jones-Bitton, and S. J. LeBlanc. 2016. Survey of reproduction management on Canadian dairy farms. J. Dairy Sci. 99:9339-9351. https://doi.org/10.3168/jds .2016-11445.

Dohoo, I. R., W. Martin, and H. E. Stryhn. 2003. Veterinary Epidemiologic Research. University of Prince Edward Island.

Edmonson, A. J., I. J. Lean, L. D. Weaver, T. Farver, and G. Webster. 1989. A body condition scoring chart for Holstein dairy cows. J. Dairy Sci. 72:68-78. https://doi.org/10.3168/jds.S0022 -0302(89)79081-0.

Flower, F. C., and D. M. Weary. 2006. Effect of hoof pathologies on subjective assessments of dairy cow gait. J. Dairy Sci. 89:139-146. https://doi.org/10.3168/jds.S0022-0302(06)72077-X.

Galvão, K. N., and J. E. P. Santos. 2010. Factors affecting synchronization and conception rate after the Ovsynch protocol in lactating Holstein cows. Reprod. Domest. Anim. 45:439-446. https://doi .org/10.1111/j.1439-0531.2008.01220.x.

Galvão, K. N., J. E. P. Santos, S. O. Juchem, R. L. A. Cerri, A. C. Coscioni, and M. Villaseñor. 2004. Effect of addition of a progesterone intravaginal insert to a timed insemination protocol using estradiol cypionate on ovulation rate, pregnancy rate, and late embryonic loss in lactating dairy cows. J. Anim. Sci. 82:3508-3517. https://doi.org/10.2527/2004.82123508x.

Green, L. E., V. J. Hedges, Y. H. Schukken, R. W. Blowey, and A. J. Packington. 2002. The impact of clinical lameness on the milk yield of dairy cows. J. Dairy Sci. 85:2250-2256. https://doi.org/10 .3168/jds.S0022-0302(02)74304-X.

Gümen, A., and B. Seguin. 2003. Ovulation rate after GnRH or PGF2 $\alpha$ administration in early postpartum dairy cows. Theriogenology 60:341-348. https://doi.org/10.1016/S0093-691X(02)01372-9.

Hockey, C., J. Morton, S. Norman, and M. McGowan. 2010. Evaluation of a neck mounted 2-hourly activity meter system for detecting cows about to ovulate in two paddock-based Australian dairy herds. Reprod. Domest. Anim. 45:e107-e117. https://doi.org/10 .1111/j.1439-0531.2009.01531.x.

Ijaz, A., M. L. Fahning, and R. Zemjanis. 1987. Treatment and control of cystic ovarian disease in dairy cattle: A review. Br. Vet. J. 143:226-237. https://doi.org/10.1016/0007-1935(87)90085-6.

Jinks, E. M., M. F. Smith, J. A. Atkins, K. G. Pohler, G. A. Perry, M D. MacNeil, A. J. Roberts, R. C. Waterman, L. J. Alexander, and T. W. Geary. 2013. Preovulatory estradiol and the establishment and maintenance of pregnancy in suckled beef cows. J. Anim. Sci. 91:1176-1185. https://doi.org/10.2527/jas.2012-5611. 
Kaim, M., A. Bloch, D. Wolfenson, R. Braw-Tal, M. Rosenberg, H. Voet, and Y. Folman. 2003. Effects of GnRH administered to cows at the onset of estrus on timing of ovulation, endocrine responses, and conception. J. Dairy Sci. 86:2012-2021. https://doi.org/10 .3168/jds.S0022-0302(03)73790-4.

Lee, C. N., J. K. Critser, and R. L. Ax. 1985. Changes of luteinizing hormone and progesterone for dairy cows after gonadotropin-releasing hormone at first postpartum breeding. J. Dairy Sci. 68:1463-1470. https://doi.org/10.3168/jds.S0022-0302(85)80984 $-\mathrm{X}$.

Leon, A. C., and M. Heo. 2009. Sample sizes required to detect interactions between two binary fixed-effects in a mixed-effects linear regression model. Comput. Stat. Data Anal. 53:603-608. https:// doi.org/10.1016/j.csda.2008.06.010.

Lewis, G. S., D. W. Caldwell, C. E. Rexroad Jr., H. H. Dowlen, and J. R. Owen. 1990. Effects of gonadotropin-releasing hormone and human chorionic gonadotropin on pregnancy rate in dairy cattle. J. Dairy Sci. 73:66-72. https://doi.org/10.3168/jds.S0022 $-0302(90) 78647-X$.

López-Gatius, F., P. Santolaria, A. Martino, F. Delétang, and F. De Rensis. 2006. The effects of GnRH treatment at the time of AI and 12 days later on reproductive performance of high producing dairy cows during the warm season in northeastern Spain. Theriogenology 65:820-830. https://doi.org/10.1016/j.theriogenology 2005.07.002.

López-Gatius, F., P. Santolaria, I. Mundet, and J. L. Yániz. 2005. Walking activity at estrus and subsequent fertility in dairy cows. Theriogenology 63:1419-1429. https://doi.org/10.1016/j theriogenology.2004.07.007.

Madureira, A. M. L., B. F. Silper, T. A. Burnett, L. Polsky, L. H. Cruppe, D. M. Veira, J. L. M. Vasconcelos, and R. L. A. Cerri. 2015. Factors affecting expression of estrus measured by activity monitors and conception risk of lactating dairy cows. J. Dairy Sci. 98:7003-7014. https://doi.org/10.3168/jds.2015-9672.

Madureira, A. M. L., T. A. Burnett, K. G. Pohler, T. G. Guida, C. P. Sanches Jr., J. L. M. Vasconcelos, and R. L. A. Cerri. 2020. Short communication: Greater intensity of estrous expression is associated with improved embryo viability from superovulated Holstein heifers. J. Dairy Sci. 103:5641-5646. https://doi.org/10.3168/jds 2019-17772.

Madureira, A. M. L., L. B. Polsky, T. A. Burnett, B. F. Silper, S. Soriano, A. F. Sica, K. G. Pohler, J. L. M. Vasconcelos, and R. L. A. Cerri. 2019. Intensity of estrus following an estradiol-progesterone-based ovulation synchronization protocol influences fertility outcomes. J. Dairy Sci. 102:3598-3608. https://doi.org/10.3168/ jds.2018-15129.

Mee, M. O., J. S. Stevenson, R. K. Scoby, and V. Folman. 1990. Influence of gonadotropin-releasing hormone and timing of insemination relative to estrus on pregnancy rates of dairy cattle at first service. J. Dairy Sci. 73:1500-1507. https://doi.org/10.3168/jds .S0022-0302(90)78817-0.

Morgan, W. F., and I. J. Lean. 1993. Gonadotrophin-releasing hormone treatment in cattle: A meta-analysis of the effects on conception at the time of insemination. Aust. Vet. J. 70:205-209. https:/ /doi.org/10.1111/j.1751-0813.1993.tb03304.x.

Nanda, A. S., W. R. Ward, P. C. Williams, and H. Dobson. 1988. Retrospective analysis of the efficacy of different hormone treatments of cystic ovarian disease in cattle. Vet. Rec. 122:155-158. https:// doi.org/10.1136/vr.122.7.155.

NRC. 2001. Nutrient Requirements of Dairy Cattle. 7th ed. Natl. Acad. Sci., Washington, DC.

Pereira, M. H. C., A. D. P. Rodrigues, R. J. De Carvalho, M. C. Wiltbank, and J. L. M. Vasconcelos. 2014. Increasing length of an estradiol and progesterone timed artificial insemination protocol decreases pregnancy losses in lactating dairy cows. J. Dairy Sci 97:1454-1464. https://doi.org/10.3168/jds.2013-7287.

Pereira, M. H. C., M. C. Wiltbank, and J. L. M. Vasconcelos. 2016. Expression of estrus improves fertility and decreases pregnancy losses in lactating dairy cows that receive artificial insemination or embryo transfer. J. Dairy Sci. 99:2237-2247. https://doi.org/10 .3168/jds.2015-9903.

Rodrigues, W. B., A. S. Silva, J. C. B. Silva, N. A. Anache, K. C. Silva, C. J. T. Cardoso, W. R. Garcia, P. Sutovsky, and E. Nogueira. 2019. Timed artificial insemination plus heat II: Gonadorelin injection in cows with low estrus expression scores increased pregnancy in progesterone/estradiol-based protocol. Animal 13:2313-2318 https://doi.org/10.1017/S1751731119000454.

Ryan, D. P., E. Kopel, M. P. Boland, and R. A. Godke. 1991. Pregnancy rates in dairy cows following the administration of a $\mathrm{GnRH}$ analogue at the time of artificial insemination or at mid-cycle post insemination. Theriogenology 36:367-377. https://doi.org/10 .1016/0093-691X(91)90465-P.

Ryan, D. P., S. Snijders, T. Condon, M. Grealy, J. Sreenan, and K. J. O'Farrell. 1994. Endocrine and ovarian responses and pregnancy rates in dairy cows following the administration of a gonadotrophin releasing hormone analog at the time of artificial insemination or at mid-cycle post insemination. Anim. Reprod. Sci. 34:179-191. https://doi.org/10.1016/0378-4320(94)90015-9.

Shephard, R. W., J. M. Morton, and S. T. Norman. 2014. Effects of administration of gonadotropin-releasing hormone at artificial insemination on conception rates in dairy cows. Anim. Reprod. Sci. 144:14-21. https://doi.org/10.1016/j.anireprosci.2013.11.004.

Silper, B. F., A. M. L. Madureira, L. B. Polsky, S. Soriano, A. F. Sica, J. L. M. Vasconcelos, and R. L. A. Cerri. 2017. Daily lying behavior of lactating Holstein cows during an estrus synchronization protocol and its associations with fertility. J. Dairy Sci. 100:8484-8495. https://doi.org/10.3168/jds.2016-12160.

Solano, L., H. W. Barkema, E. A. Pajor, S. Mason, S. J. LeBlanc, J. C. Zaffino Heyerhoff, C. G. R. Nash, D. B. Haley, E. Vasseur, D. Pellerin, J. Rushen, A. M. de Passillé, and K. Orsel. 2015. Prevalence of lameness and associated risk factors in Canadian HolsteinFriesian cows housed in freestall barns. J. Dairy Sci. 98:6978-6991. https://doi.org/10.3168/jds.2015-9652.

Stevenson, J. S., E. P. Call, R. K. Scoby, and A. P. Phatak. 1990. Double insemination and gonadotropin-releasing hormone treatment of repeat-breeding dairy cattle. J. Dairy Sci. 73:1766-1772. https://doi.org/10.3168/jds.S0022-0302(90)78855-8.

Stevenson, J. S., S. L. Hill, R. L. Nebel, and J. M. DeJarnette. 2014 Ovulation timing and conception risk after automated activity monitoring in lactating dairy cows. J. Dairy Sci. 97:4296-4308. https://doi.org/10.3168/jds.2013-7873.

Stevenson, J. S., and S. L. Pulley. 2016. Feedback effects of estradiol and progesterone on ovulation and fertility of dairy cows after gonadotropin-releasing hormone-induced release of luteinizing hormone. J. Dairy Sci. 99:3003-3015. https://doi.org/10.3168/jds .2015-10091.

Thatcher, W. W., M. Drost, J. D. Savio, K. L. Macmillan, K. W. Entwistle, E. J. Schmitt, R. L. De la Sota, and G. R. Morris. 1993. New clinical uses of GnRH and its analogues in cattle. Anim. Reprod. Sci. 33:27-49. https://doi.org/10.1016/0378-4320(93)90105 -Z.

Valenza, A., J. O. Giordano, and G. Lopes. JrVincenti, L., M. C. Amundson, and P. M. Fricke. 2012. Assessment of an accelerometer system for detection of estrus and treatment with gonadotropin-releasing hormone at the time of insemination in lactating dairy cows. J. Dairy Sci. 95:7115-7127. https://doi.org/10.3168/ jds.2012-5639.

\section{ORCIDS}

Tracy A. Burnett @ https://orcid.org/0000-0003-2417-4016 Augusto M. L. Madureira (ํ) https://orcid.org/0000-0001-9696-8478 Janet W. Bauer @ https://orcid.org/0000-0002-3301-7082 Ronaldo L. A. Cerri $\odot$ https://orcid.org/0000-0002-8169-8900 